\title{
The Complete Genome of Probiotic Lactobacillus sakei Derived from Plateau Yak Feces
}

Kun Li 1,2,3, Juanjuan Liu ${ }^{1}$, Zhibo Zeng ${ }^{1}$, Muhammad Fakhar-e-Alam Kulyar ${ }^{1}$, Yaping Wang ${ }^{1}$, Aoyun Li ${ }^{1}$, Zeeshan Ahmad Bhutta ${ }^{4}$, Amjad Islam Aqib 5, Muhammad Shahzad ${ }^{6}$, Jiakui Li 1,7,* and Desheng $\mathrm{Qi}^{3}$

1 College of Veterinary Medicine, Huazhong Agricultural University, Wuhan 430070, China; kl@mail.hzau.edu.cn (K.L.); LJJ15927022497@163.com (J.L.); zengzzhibo@163.com (Z.Z.); fakhar@webmail.hzau.edu.cn (M.F.A.K.); 15827205277@163.com (Y.W.); aoyunli1993@163.com (A.L.)

2 Institute of Traditional Chinese Veterinary Medicine, College of Veterinary Medicine, Nanjing Agricultural University, Nanjing 210095, China

3 Department of Animal Nutrition and Feed Science, College of Animal Science and Technology, Huazhong Agricultural University, Wuhan 430070, China; qds@mail.hzau.edu.cn

4 The Royal (Dick) School of Veterinary Studies, University of Edinburgh, Easter Bush Campus, Midlothian EH25 9RG, UK; doctorzeeshan94@gmail.com

5 Department of Medicine Cholistan, University of Veterinary \& Animal Sciences, Bahawalpur 64100, Pakistan; amjadwaseer@cuvas.edu.pk

6 Department of Pathology, Faculty of Veterinary \& Animal Sciences, The Islamia University of Bahawalpur, Bahawalpur 63100, Pakistan; m.shahzad@iub.edu.pk

7 Laboratory of Detection and Monitoring of Highland Animal Disease, Tibet Agriculture and Animal Husbandry College, Linzhi 860000, China

* Correspondence: lijk210@mail.hzau.edu.cn

Received: 9 November 2020; Accepted: 18 December 2020; Published: 21 December 2020

\begin{abstract}
Probiotic bacteria are receiving increased attention due to the potential benefits to their hosts. Plateau yaks have resistance against diseases and stress, which is potentially related to their inner probiotics. To uncover the potential functional genes of yak probiotics, we sequenced the whole genome of Lactobacillus sakei (L. sakei). The results showed that the genome length of L. sakei was $1.99 \mathrm{Mbp}$, with 1943 protein coding genes (21 rRNA, 65 tRNA, and 1 tmRNA). There were three plasmids found in this bacteria, with 88 protein coding genes. EggNOG annotation uncovered that the L. sakei genes were found to belong to J (translation, ribosomal structure, and biogenesis), L (replication, recombination, and repair), G (carbohydrate transport and metabolism), and K (transcription). GO annotation showed that most of the $L$. sakei genes were related to cellular processes, metabolic processes, biological regulation, localization, response to stimulus, and organization or biogenesis of cellular components. CAZy annotation found that there were 123 CAZys in the L. sakei genome, with glycosyl transferases and glycoside hydrolases. Our results revealed the genome characteristics of L. sakei, which may give insight into the future employment of this probiotic bacterium for its functional benefits.
\end{abstract}

Keywords: probiotic; yak; Lactobacillus sakei; genome; sequencing

\section{Introduction}

Probiotics are live microbes which confer health benefits to their host by supporting a healthy gut microbiota, which plays an important role in the digestive system, and the alleviation of symptoms of disease [1,2]. Lactobacillus sakei (L. sakei) is a representative probiotic that is commonly isolated from fermented foods [3]. This nonpathogenic lactic acid bacterium has been found to prevent the growth 
of pathogens like Listeria monocytogenes, Escherichia coli O157: H7, and Brochothrix thermosphacta in meat-related products [4]. Our previous study also found that L. sakei inhibit Staphylococcus aureus, Pasteurella multocida, E. coli, and Salmonella in vitro [5]. Alongside their antimicrobial effects, some L. sakei strains have been found to contribute to host health, for instance through amelioration of skin inflammation and collagen-induced arthritis [6], and through antioxidant, anti-colitis, anticancer, and anti-obesity effects [7-10]. L. sakei has also been found to have probiotic effects on children with atopic eczema/dermatitis [11].

Yaks are typical economically important bovine animals on the Qinghai-Tibetan Plateau [12,13]. These ruminants are resilient, in that they live and thrive in a hypoxic environment (oxygen content: 14.9 11.44\%), which is cold (annual average temperature under $0 \sim 10{ }^{\circ} \mathrm{C}$ ) and on a high plateau (3000 6000 m), with no guarantee of sufficient food. Their ability to adapt to such harsh environmental factors is facilitated by their large lungs, large heart, and efficient foraging and energy metabolism [14], as well as their gut microbiota which contributes significantly to live at a high altitude; also, a significant difference of microbiota was found between yaks in high and low plateaus $[15,16]$. The microbiota is generally recognized to play an important role in the functionality of immune systems, regulating intestinal motility, gut barrier homeostasis, and nutrient metabolism [17]. Previously, the genome of L. sakei has been derived from various different sources, including kimchi, meat or meat products, raw sausages, cacao beans, and potatoes, among others [3,18-21]. However, until now, there has been limited knowledge of the genome characteristics of L. sakei isolated from plateau animals. It is hypothesized that adaption to the critical environment of the Qinghai-Tibetan Plateau may potentially be related to gut bacteria and adapted micro-organisms, which may be profoundly influenced by the structure of their genomes. Therefore, we undertook this work to uncover the genome information of L. sakei isolated from high remote plateau yaks for the first time.

\section{Materials and Methods}

\subsection{Ethics Statement}

The experiments were performed under the guidance and approval of the Laboratory Animals Research Centre of Hubei, Tibet, and the ethics committee of Huazhong Agricultural University in P.R. China (Permit number 4200695757).

\subsection{Probiotics Strain}

L. sakei (Accession: MT712200) was isolated from the feces of a healthy female yak in Nyingchi, Tibet, China, using de Man, Rogosa and Sharp agar (Qingdao Reagents, Qingdao, China) media. It was identified by amplifying and sequencing the universal 16S ribosomal RNA gene, and comparing its sequence to the kimchi isolate from South Korea (AB650590.1) [5] in the NCBI database (https://blast.ncbi.nlm.nih.gov/Blast.cgi?PROGRAM=blastn\&PAGE_TYPE=BlastSearch\& LINK_LOC=blasthome). The bacterium isolate was cryopreserved at $-80^{\circ} \mathrm{C}$ for further analysis.

\subsection{Genome DNA Extraction}

L. sakei was cultured in $30 \mathrm{~mL}$ fresh MRS (Qingdao Reagents, Qingdao, China) medium in a $50 \mathrm{~mL}$ sterile tube in an incubator for $24 \mathrm{~h}$ at $37^{\circ} \mathrm{C}$, and the bacteria harvested by centrifugation at $8000 \mathrm{rpm}$ for $40 \mathrm{~min}$. The bacterial pellet was washed with sterile phosphate buffer and centrifuged at $8000 \mathrm{rpm}$ for $40 \mathrm{~min}(n=3)$. Total genomic DNA was extracted from the bacteria pellet using a QIAam 3323 Blood \& Cell Culture DNA Mini Kit (QIAGEN, Hilden, Germany), following the manufacturer's instructions. The integrity of the purified DNA was analyzed by fractionation in a $2.0 \%$ agarose gel, while DNA purity (OD260/OD280 ratio) was determined by Nanodrop 3300 Fluorospectrometer (Thermo Fisher Scientific, Wuhan, China). The DNA concentration was measured using an Invitrogen Qubit 3.0 (Thermo Fisher Scientific, Wuhan, China). 


\subsection{Library Construction and Sequencing}

Extraction and purification of targeted DNA fragments was performed using a BluePippin automatic nucleic acid gel-cutting instrument (Sage Science, Beverly, MA, USA). DNA samples were fragmented, end-repaired, purified, end-linked with barcodes, purified, and linked with a sequencing adapter by employing an NBD103 and NBD114 kit (Oxford Nanopore Technologies, Oxford, UK) to construct the DNA library. The sequence library concentration was measured using an Invitrogen Qubit 3.0 (Thermo Fisher Scientific, Wuhan, China). Sequencing was carried out by utilizing a MinION Nanopore sequencer (Oxford Nanopore Technologies, Personalbio, Shanghai, China) and Illumina HiSeqTM 2000 sequencer (Personalbio, Shanghai, China).

\subsection{Sequencing Data and Quality Control}

After obtaining the Nanopore and Illumina sequence of the generated raw data, quality control was performed by using the Quality Score and content distribution. The base Q-Score is a commonly used evaluation parameter to represent reliability and accuracy. The base content distribution was analyzed to detect the separation of AT and GC. Reads with connectors and low-grade reads (proportion of $N>10 \%$, over half of a read $Q$-Score $\leq 10$ ) were removed to ensure high quality and accuracy for the subsequent analysis.

\subsection{Genome Assembly, Annotation, and Phylogenetic Analysis}

The SPAdes genome assembler (v3.11.1) and A5-miseq (v20160825) were used to assemble sequencing data generated by Illumina [22,23]. HGAP4 and CANU (V1.6) were utilized to assemble sequencing data generated by Nanopore [24,25]. Then, MUMmer (v4) was employed to retrieve previously assembled results [26], while pilon (v1.22) was used to correct presently assembled results [27]. The annotation of the L. sakei genome was performed via GeneMarkS (v4.32) for prediction of protein-coding genes [28]; tRNAscan-SE (v1.3.1) for prediction of tRNA [29]; and Barrnap (0.9-dev) (https://github.com/tseemann/barrnap) for prediction of rRNA. All other RNAs were predicted by blasting with the Rfam database [30]. RepeatMasker (v4.0.3) (http://www.repeatmasker.org/) was used for analyzing repetitive sequences. A phylogenetic tree was constructed based on 16S rDNA gene sequences from available Lactobacillus strains, including L. sakei (MT814885.1, MK640920.1, MF688992.1, MF688992.1, KP179418.1, KM267631.1, KF559316.1, HQ992696.1, HQ022862.1, EU755262.1), L. johnsonii (M99704.1, NR_117574.1), L. paralimentarius (NR_043096.1), L. ultunensis (NR_042802.1), L. harbinensis (NR_041263.1), L. hominis (NR_125548.1), L. acetotolerans (M58801.1), L. reuteri (MT764998.1), and Pediococcus damnosus (D87678.1). A whole genome-based phylogenetic tree was constructed based on available Lactobacillus strains, including L. sakei (CP032633, CP046037, LT960781, LT107933, NZ_CP05969, NZ_LT960788, NZ_LP022709), and P. damnosus (CP012294).

\subsection{Functional Analysis}

All the protein-coding genes were blasted in the database of $\mathrm{Nr}$ (ftp://ftp.ncbi.nih.gov/blast/db/), Carbohydrate-Active enZYmes Database (http://www.cazy.org), Swiss-Prot (http://www.uniprot.org/), GO (http://www.geneontology.org/), eggNOG/COG (http://www.ncbi.nlm.nih.gov/COG/), KOG (ftp: //ftp.ncbi.nih.gov/pub/COG/KOG/kyva), KEGG (http://www.genome.jp/kegg/), and Pfam (http://pfam. xfam.org/), respectively, to perform gene function analysis of L. sakei's genome. KEGG pathway annotation was performed using KAAS (Ver. 2.1) [31].

\subsection{Plasmid Analysis}

The annotations of L. sakei plasmids and protein-coding genes were blasted in the databases similar to those used for genome analysis. 


\subsection{Genome and Plasmid Comparison}

In order to determine the genomic structure and plasmids of $L$. sakei, the genome sequence data was analyzed in comparison to the NCBI genome database (https://www.ncbi.nlm.nih.gov/genome/ ?term=Lactobacillus+sakei).

\section{Results}

\subsection{Raw Data Deposit}

The sequences of L. sakei's genome and plasmids were submitted to the NCBI database with the accession numbers: chromosome (CP064817) and plasmids (MW265923, MW265924, MW265925).

\subsection{Sequencing Information and Quality Control Results}

A total of 113,051 filtered reads $(96.29 \%)$, with a total of $1,671,594,841 \mathrm{bp}$, were obtained through Nanopore sequencing (Table 1). Among these, low-quality reads were less than 5000 (Figure 1A). Illumina sequencing showed that all the read error rates were less than 0.00035 (Figure 1B). The distribution of $\mathrm{A} / \mathrm{T} / \mathrm{C} / \mathrm{G}$ contents were all nearly horizontal, except in the first few reads (presented as peaks) (Figure 1C), because of preference for random primer sequences in the initial reads. Overall, the clean reads of $L$. sakei were as high as $99.79 \%$ (7074292/7089390), with a total base of 1,061,058,974 bp (Table 2, Figure 1D). The Q-Scores of Q20 and Q30 were 97.95\% and 93.42\%, respectively (Table 2), revealing the high quality and accuracy of the $L$. sakei genome sequence reads.

Table 1. Sequencing information of L. sakei via Nanopore.

\begin{tabular}{ccccccc}
\hline Reads Type & Bases (bp) & $\begin{array}{c}\text { Reads } \\
\text { Number }\end{array}$ & $\begin{array}{c}\text { Reads Mean } \\
\text { Length (bp) }\end{array}$ & Reads N50 (bp) & $\begin{array}{c}\text { Longest } \\
\text { Reads (bp) }\end{array}$ & $Q$-Score \\
\hline Raw & $1,722,592,614$ & 117,399 & $14,672.97$ & 28,556 & 179,164 & \\
Filtered & $1,671,594,841$ & 113,051 & $14,786.2$ & 28,642 & 179,164 & $\geq 7$ \\
\hline
\end{tabular}
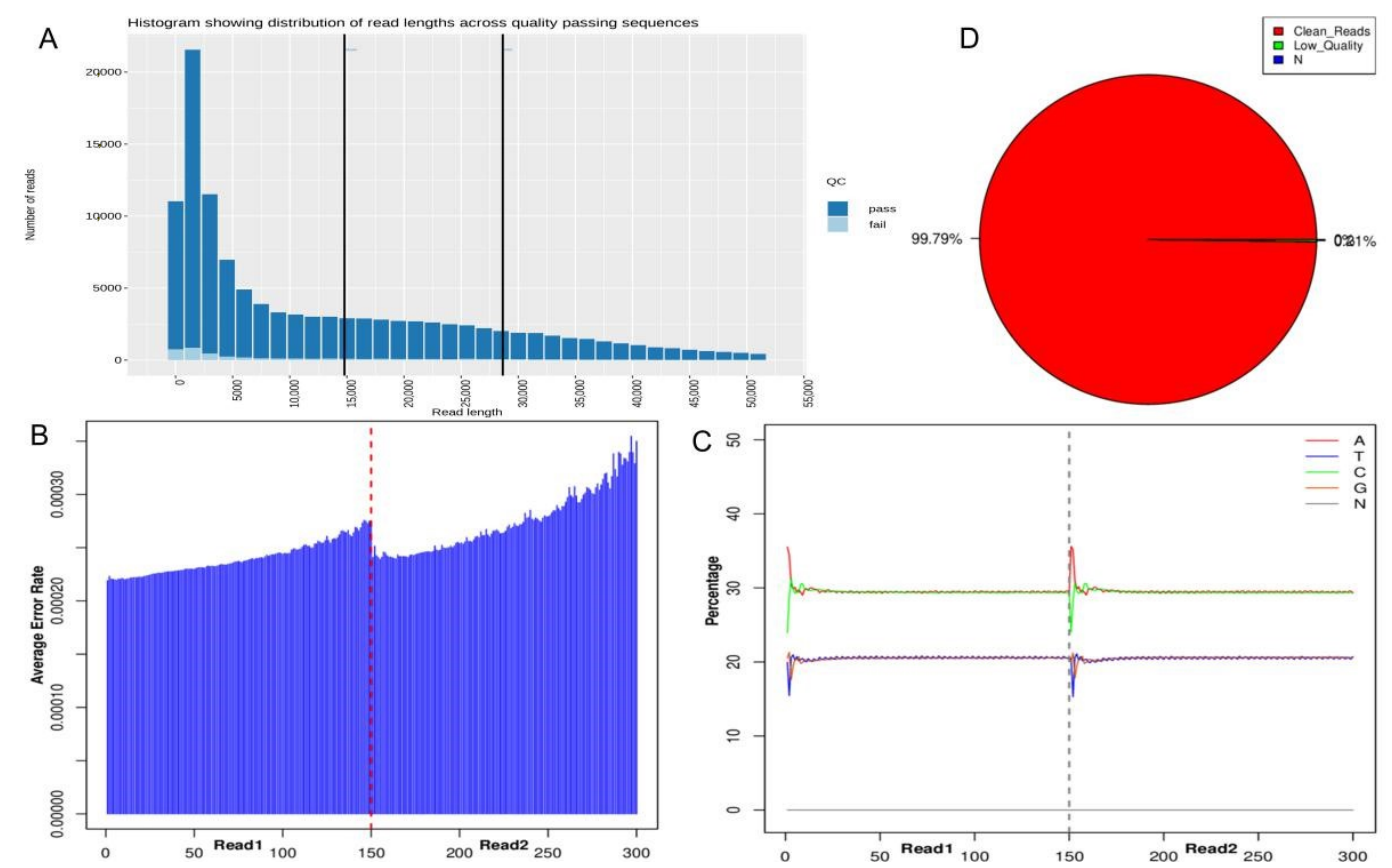

Figure 1. Sequencing quality control information of Lactobacillus sakei (L. sakei). (A) Histogram of reading lengths and number distribution of sequencing; (B) Base sequencing error rate distribution map; (C) Bases (ATGC) content distribution map; (D) Original data composition map. 
Table 2. Sequencing information of L. sakei via Illumina.

\begin{tabular}{ccccccc}
\hline Total Reads & Clean Reads & Percentage (\%) & Clean Bases & GC Content (\%) & Q20 (\%) & Q30 (\%) \\
\hline $7,089,390$ & $7,074,292$ & $99.79 \%$ & $1,061,058,974$ & $41.0 \%$ & $97.95 \%$ & $93.42 \%$ \\
\hline
\end{tabular}

\subsection{Genome Assembly, Annotation and Phylogenetic Tree}

A total of 1,989,121 bp (1.99 Mbp) were sequenced from L. sakei's circular genome, with a GC content of $41.1 \%$. The sequencing depth of $L$. sakei was 533 , which could reduce false positives and sequencing error rates. Prodigal-2.6.2 (https://github.com/hyattpd/prodigal/wiki) was used to perform the gene prediction of L. sakei, and the results showed that the total gene length was $1,776,396 \mathrm{bp}$ with an average gene length of $875 \mathrm{bp}$ (Table 3). The GC content of L. sakei genes was observed to be $41 \%$, with an intergenetic region length of 212,724. Gene density and Gene/Genome (\%) were 1045 and $89 \%$, respectively. In total, L. sakei had 1943 protein coding genes, 21 rRNA (equal number of $5 \mathrm{~S}$ rRNA, 16S rRNA, 23S rRNA), 65 tRNA, and 1 tmRNA. A total of 103 repeated sequences were observed, in which 49 sequences were located in rRNA, 45 were simple repeated sequences, and 9 were low-complexity repeat sequences. The L. sakei genome map was drawn using cgview (Figure 2) [32]. The 16s rRNA phylogenetic tree showed that the L. sakei yak isolate is the closest evolutionary relative of L. sakei (MK640920.1) (Figure 3). The whole genome-based phylogenetic tree showed that the L. sakei yak isolate is the closest evolutionary relative of L. sakei (NZ_CP059697) (Figure S1).

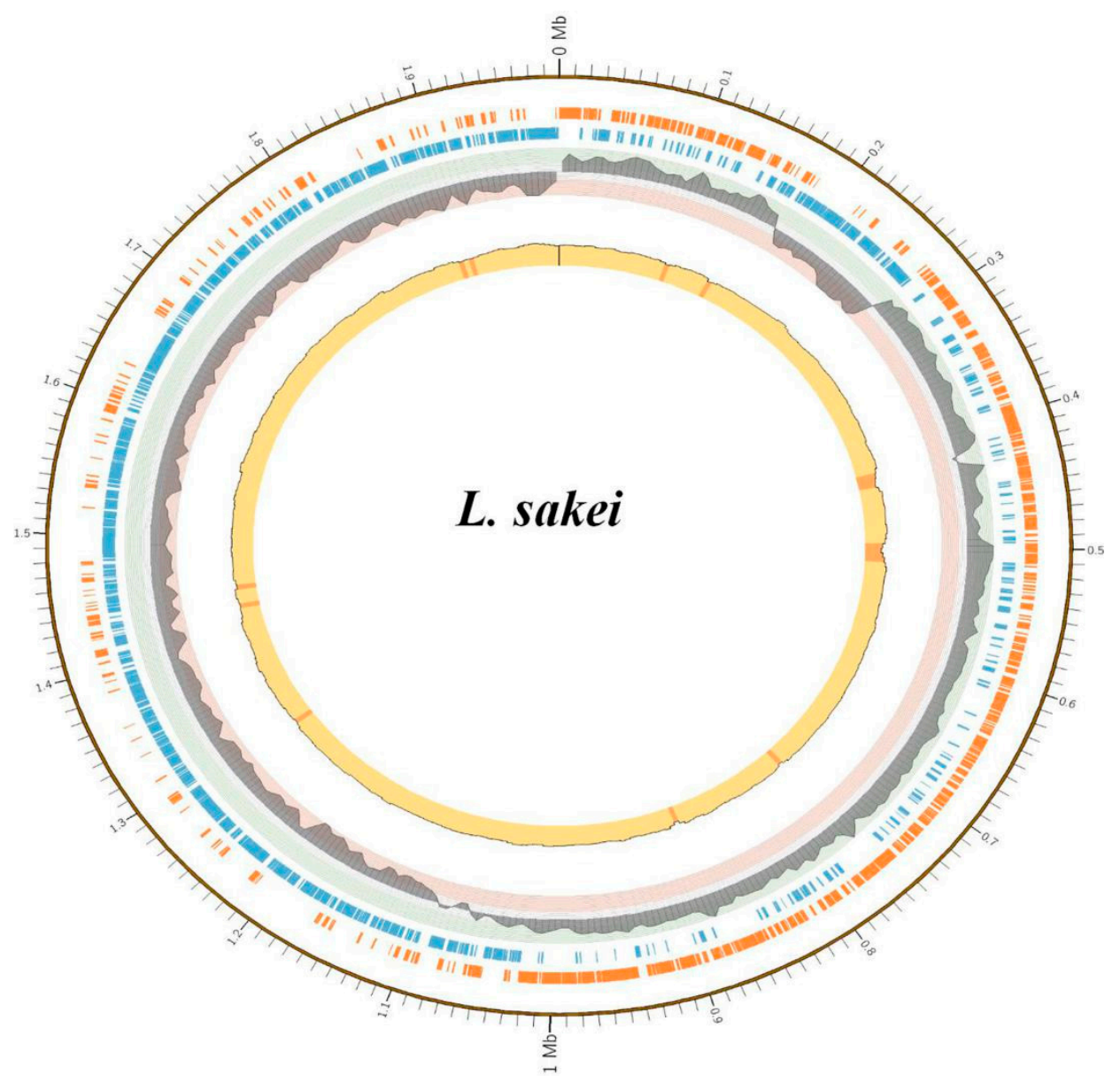

Figure 2. The genome circular map of L. sakei. 


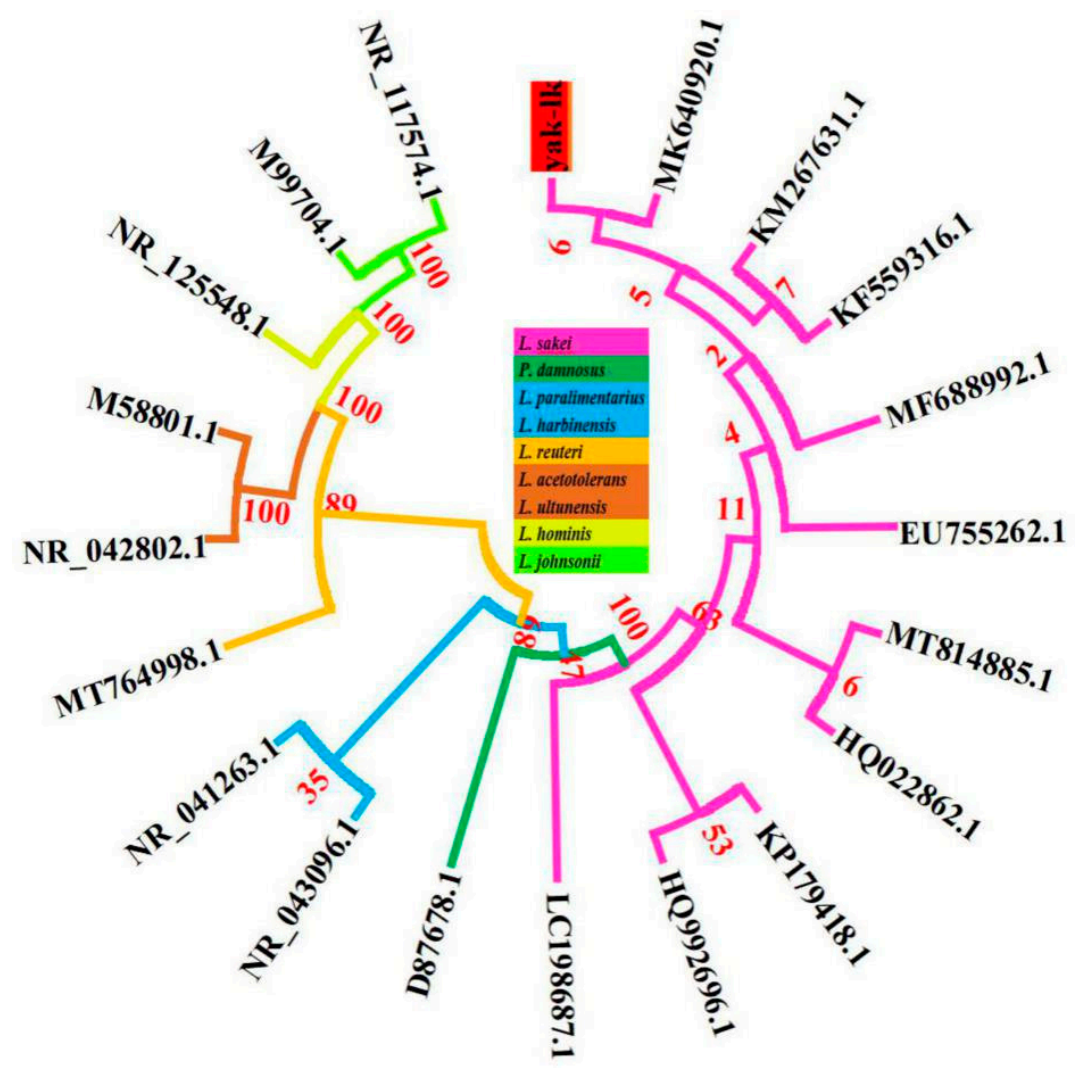

Figure 3. Phylogenetic tree of the L. sakei yak isolate and references strains. The tree was constructed using software MEGA 6.0 by the neighbor-joining method, based on 16S rDNA gene sequences with 1000 replications in bootstrap testing.

Table 3. Statistical results of the gene prediction of L. sakei.

\begin{tabular}{cc}
\hline Category & Property \\
\hline Total gene length $(\mathrm{bp})$ & $1,776,396$ \\
Average gene length $(\mathrm{bp})$ & 875 \\
GC content in the gene region & 41 \\
Gene density (genes/Mb) & 1045 \\
Gene/Genome $(\%)$ & 89 \\
Intergenetic region length & 212,724 \\
Protein coding genes & 1943 \\
rRNA genes & 21 \\
tRNA genes & 65 \\
Gene density(genes/Mb) & 1045 \\
Gene/Genome $(\%)$ & 89 \\
Intergenetic region length & 212,724 \\
Sequencing depth & 533 \\
\hline
\end{tabular}

\subsection{Functional Analysis}

EggNOG annotation uncovered that the mainly known genes of L. sakei genes were found to belong to J (translation, ribosomal structure, and biogenesis), L (replication, recombination, and repair), G (carbohydrate transport and metabolism), and K (transcription) (Figure 4). GO annotation showed that most of the L. sakei genes are related to biological processes, metabolic processes, biological regulation, localization, response to stimuli, and cellular component organization or biogenesis. In terms of function, most genes contribute to cell structural functions, including membrane and organelle architecture. In terms of cell molecular functions, the majority of genes were related to enzymatic catalytic activity, ligand, and transporting activities (Figure 5). 


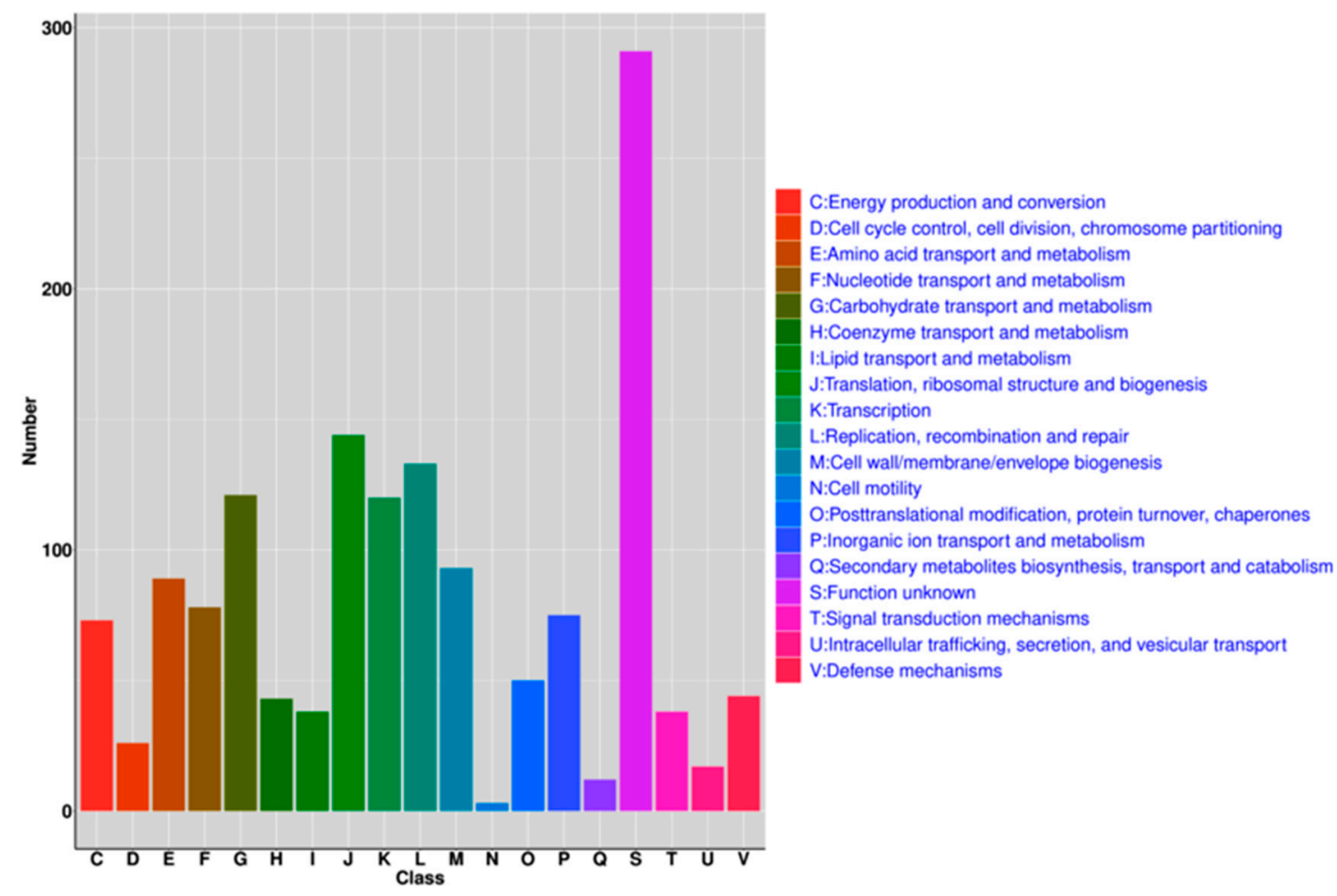

Figure 4. The eggNOG annotation of the L. sakei genome.

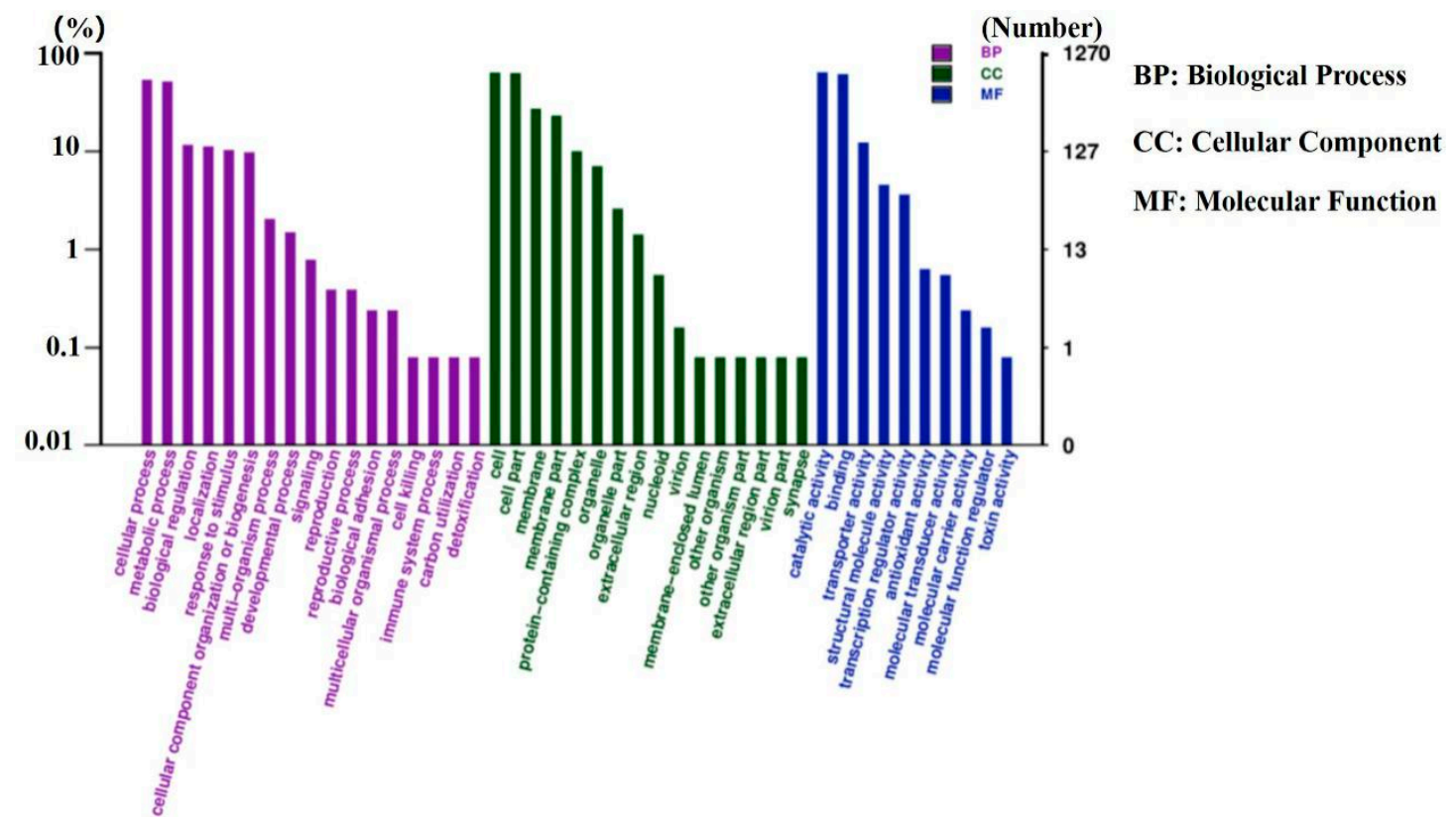

Figure 5. The GO annotation of the L. sakei genome.

CAZy annotation found that there are 123 CAZys in the L. sakei genome, including glycosyl transferases and glycoside hydrolase (Figure 6). Signal peptides were analyzed via SignalP (v4.1), with $24.61 \%$ (493/2003) coding genes containing signal peptides [33]. Transmembrane domain prediction performed by employing TMHMM (Server v2.0) found that $28.61 \%$ (573/2003) of coding genes have transmembrane domains [34]. Sequence blasting of genes with the NCBI database, and protein-coding via diamond (v0.9.10.111), indicated 99.70\% (1997/2003) of genes were protein-coding genes [35] while blasting with the Swiss-Prot database showed $65.60 \%$ (1314/2003) of the gene code for proteins. 
Pfam (http://pfam.janelia.org/) blasting revealed that $72.89 \%$ (1460/2003) of the encoded proteins contain PFAM domains [36].

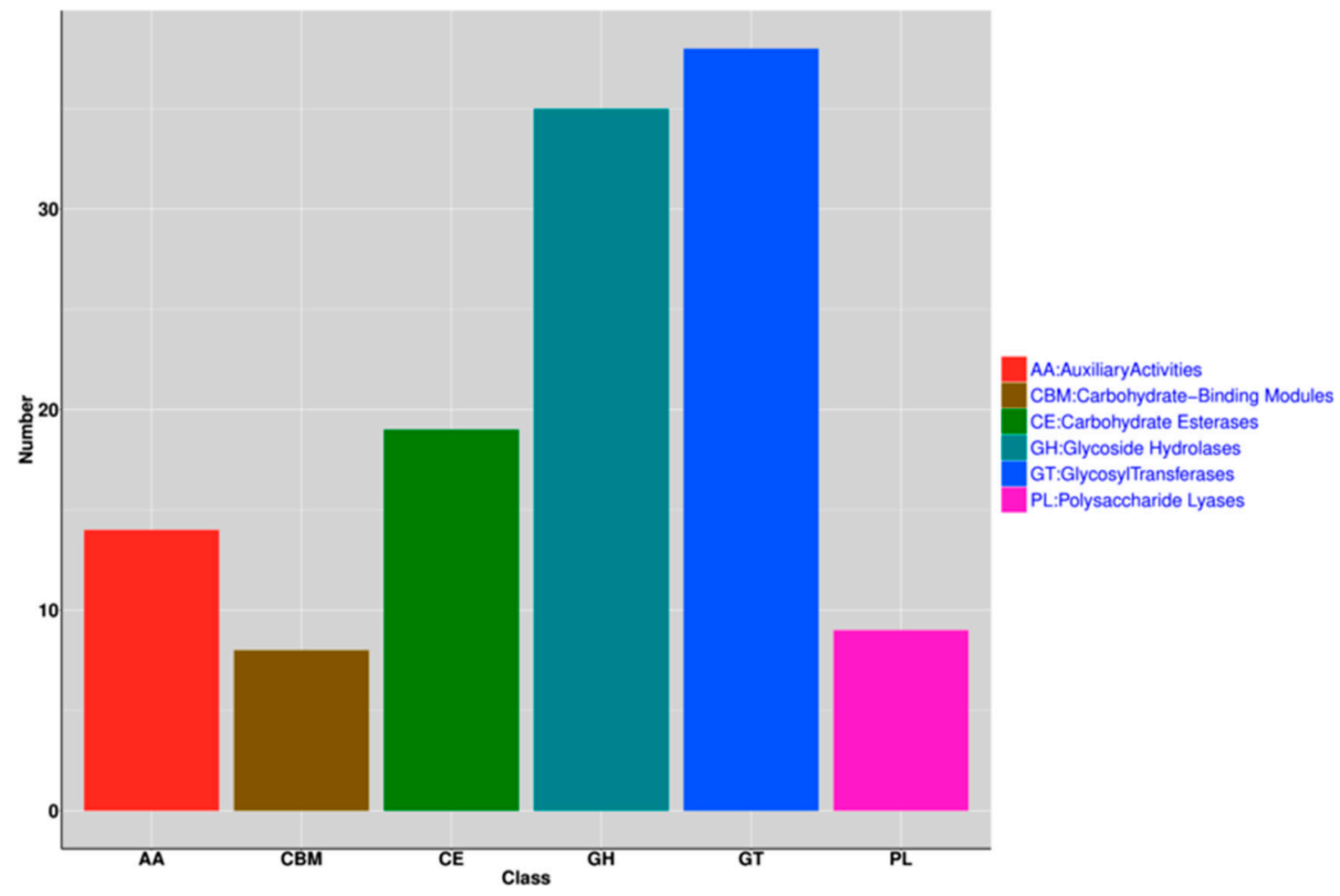

Figure 6. Analysis of CAZy in the L. sakei genome.

KEGG annotation found that the biosynthesis of secondary metabolites, the metabolism of amino acids, carbohydrates, energy, glycans, lipids, cofactors, vitamins, terpenoids, polyketides, and nucleotides, and xenobiotic metabolism and biodegradation, were the dominant functions of the genes (Figure 7). KEGG pathways analysis revealed 72 "ko-" related reference pathways of metabolism (glycolysis/gluconeogenesis, pentose phosphate, pentose and glucuronate interconversions, fructose and mannose, galactose, purine, pyrimidine, amino acids, alanine, aspartate, glutamate, glycine, serine, threonine, cysteine, methionine and tyrosine, selenocompound, glutathione, starch, sucrose, amino sugar and nucleotide sugar, glycerophospholipid, pyruvate, glycerolipid, glyoxylate and dicarboxylate, propanoate, butanoate, one carbon pool by folate, methane, thiamine, nicotinate and nicotinamide, biotin, drug, carbon, fatty acids); biosynthesis (fatty acids, amino acids, phenylalanine, streptomycin, peptidoglycan, pantothenate and CoA, folate, terpenoid backbone, aminoacyl-tRNA); degradation (fatty acids, chloroalkane and chloroalkene, naphthalene, aromatic compounds, ribosomes, RNA), and other pathways, like oxidative phosphorylation, photosynthesis, carbon fixation in photosynthetic organisms, carbon fixation pathways in prokaryotes, $\beta$-Lactam resistance, cationic antimicrobial peptide (camp) resistance, $\mathrm{ABC}$ transporters, two-component system, quorum sensing, phosphotransferase system (PTS), RNA polymerase, RNA replication, protein export, bacterial secretion system, base excision repair, nucleotide excision repair, mismatch repair, homologous recombination, cell cycle-caulobacter, staphylococcus aureus infection, longevity regulating pathway-worm, glucagon signaling pathway, and central carbon metabolism in cancer. 


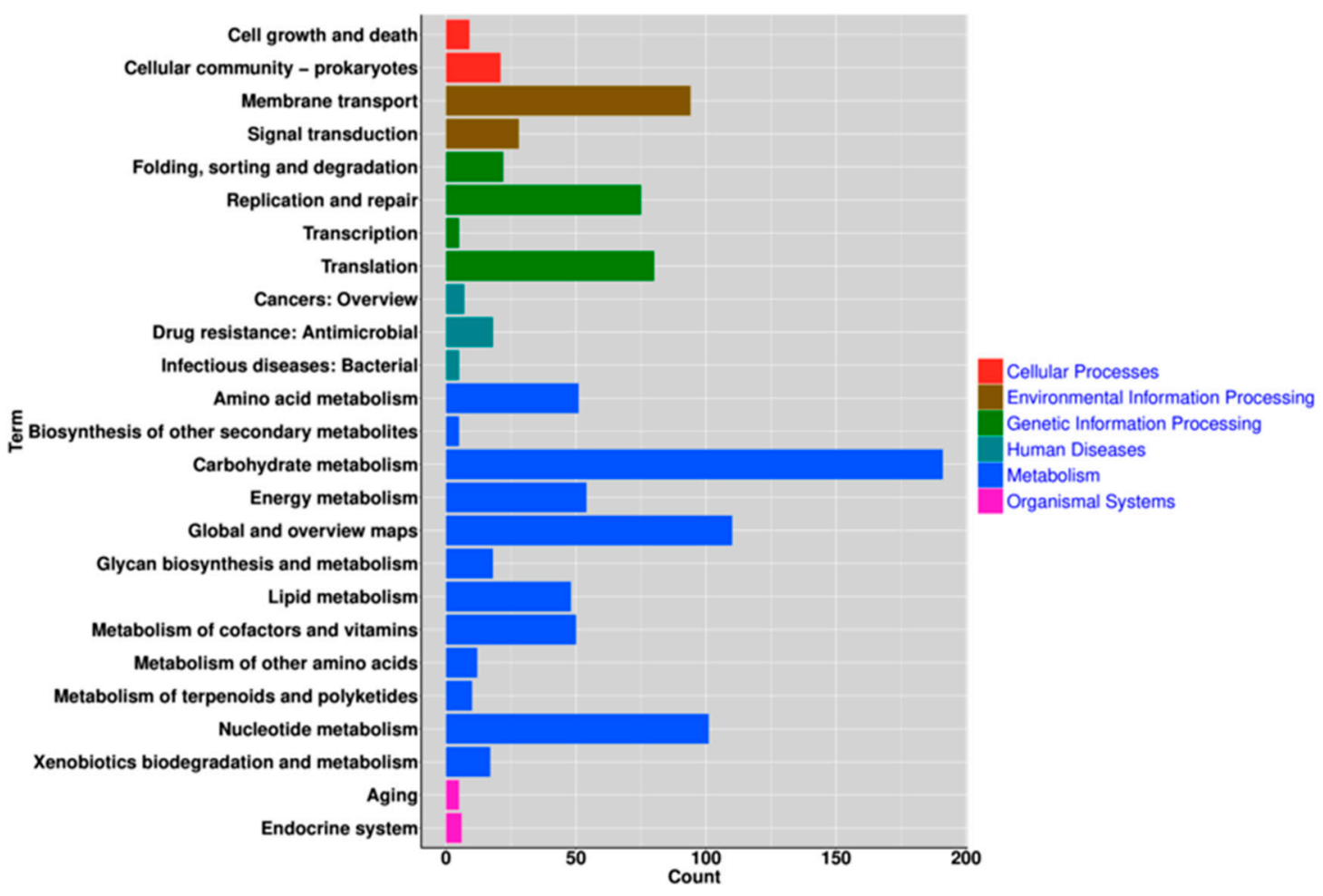

Figure 7. The KEGG annotation of the L. sakei genome.

\subsection{Plasmid Analysis}

There were three circular plasmids (LS-P1, LS-P2, LS-P3) in L. sakei (Figure 8). The gene length of those three plasmids was 74,183, 8784 and $4034 \mathrm{bp}$, respectively. The GC content in LS-P1 was 40\%, while a slightly lower GC content was found in LP-P2 and LS-P3 (35\%; 35\%). Prokka (v1.12) was used to annotate the L. sakei plasmids [37]; LS-P1 encoded for 75 proteins, including Lactococcin A secretion protein LcnD, IS3 family transposase IS1163, and Asparagine synthetase B. LS-P2 and LS-P3 encoded for 7 and 6 hypothetical proteins, respectively.
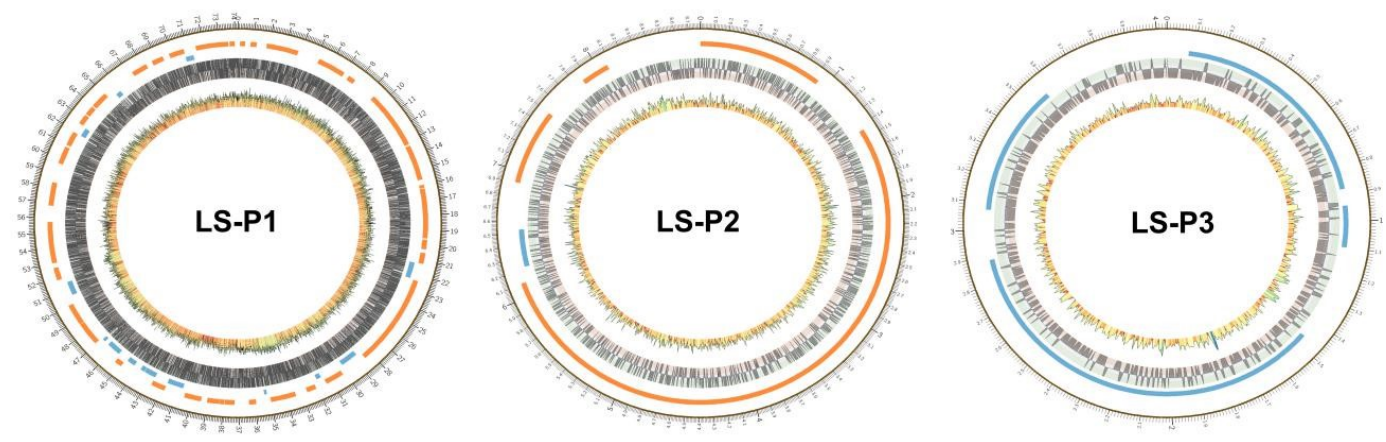

Figure 8. The genome circular maps of L. sakei plasmids.

\subsection{Genome and Plasmid Comparison Analysis}

The genome length (1.99 Mbp), GC content (41.1\%), coding genes (1943), and plasmids $(n=3)$ of yak L. sakei were compared to other L. sakei strains' genomes in the databases. About 54 of the previously reported strains had comparable genome length (1.82 2.19 Mbp), GC content (40.6 41.3\%), coding genes (1752 3532), and plasmids (0 3) (Table 4). On the other hand, 42 of the available L. sakei genomes had divergent plasmid length (1526 84,581), GC content (34.0 44.5\%), and coding genes (2 80) (Table 5). 
Table 4. Characteristics' analysis of available L. sakei genome.

\begin{tabular}{|c|c|c|c|c|c|}
\hline Accession No. & Size (Mbp) & GC (\%) & Genes No. & Plasmids No. & Origin \\
\hline СР064817 & 1.99 & 41.1 & 1943 & 3 & Yak feces \\
\hline NZ_CP046037.1 & 2.02 & 41.1 & 1904 & 2 & Kimchi \\
\hline NZ_CP025839.1 & 2.10 & 41.1 & 1964 & 0 & Kimchi \\
\hline NZ_CP048116.1 & 1.99 & 41.0 & 1842 & 0 & Kimchi \\
\hline NZ_CP025136.1 & 2.03 & 41.2 & 1936 & 2 & Kimchi \\
\hline NZ_CP025206.1 & 2.04 & 41.0 & 1916 & 2 & Kimchi \\
\hline NZ_CP020806.1 & 2.08 & 41.2 & 1975 & 2 & Kimchi \\
\hline NZ_CP025203.1 & 2.04 & 41.2 & 1913 & 2 & Kimchi \\
\hline JRFY01000024.1 & 2.19 & 40.6 & 1869 & $\sim$ & Kimchi \\
\hline NZ_LT960781.1 & 2.10 & 41.1 & 2024 & 2 & Sausage \\
\hline NZ_LT960790.1 & 2.01 & 41.3 & 1886 & 2 & Sausage \\
\hline NZ_LT907930.1 & 1.82 & 41.0 & 3532 & 0 & Sausage \\
\hline NZ_LT907929.1 & 1.88 & 41.1 & 1752 & 0 & Sausage \\
\hline NZ_ASTI01000039.1 & 2.03 & 40.9 & 1919 & 1 & Sausage \\
\hline NZ_CP059697.1 & 2.06 & 41.0 & 2002 & 1 & Fermented vegetables \\
\hline NZ_CP032652.1 & 2.02 & 41.2 & 1908 & 1 & Fermented vegetables \\
\hline NZ_CP032640.1 & 2.02 & 41.2 & 1907 & 1 & Fermented vegetables \\
\hline NZ_MK̄DM00000000.1 & 2.02 & 40.9 & 1934 & $\sim$ & Meat \\
\hline NZ_MKDO00000000.1 & 2.03 & 40.9 & 1938 & $\sim$ & Meat \\
\hline NZ_MKDC00000000.1 & 1.94 & 41.1 & 1892 & $\sim$ & Meat \\
\hline NZ_MKDN00000000.1 & 1.91 & 41.0 & 1838 & $\sim$ & Meat \\
\hline NZ_AZFG01000049.1 & 1.99 & 41.0 & 1923 & $\sim$ & Meat \\
\hline NZ_LT907933.1 & 1.98 & 41.0 & 1864 & 0 & Horse meat \\
\hline NZ_LT960788.1 & 2.04 & 41.1 & 1936 & 1 & Beef carpaccio \\
\hline NZ_LT960784.1 & 2.06 & 41.1 & 1928 & 3 & Beef carpaccio \\
\hline NZ_CP022709.1 & 2.08 & 41.2 & 1955 & 2 & Water \\
\hline NZ_LSFF00000000.1 & 2.01 & 41.0 & 1929 & $\sim$ & Mukeunji \\
\hline NZ_CP032633.1 & 2.02 & 41.2 & 1909 & 1 & Raw cow milk \\
\hline NZ_CP032635.1 & 2.02 & 41.2 & 1909 & 1 & Raw cow milk \\
\hline NZ_AP017931.1 & 1.99 & 41.2 & 1898 & 3 & Microbial mat material \\
\hline NZ_CP020459.1 & 2.06 & 41.0 & 1921 & 2 & Food \\
\hline NZ_LT960777.1 & 1.96 & 41.2 & 1813 & 3 & Human feces \\
\hline NZ_CABMJT000000000.1 & 1.96 & 41.2 & 1813 & $\sim$ & Human gut \\
\hline NZ_OVTU00000000.1 & 2.06 & 40.8 & 1986 & $\sim$ & Potatoes \\
\hline NZ_OKRC00000000.1 & 2.03 & 40.9 & 1972 & $\sim$ & Potatoes \\
\hline NZ_CABFKU000000000.1 & 2.00 & 41.0 & 1923 & $\sim$ & Human nasopharynx \\
\hline NZ_SCIF00000000.1 & 1.98 & 41.0 & 1915 & $\sim$ & Bovine \\
\hline NZ_QOSE00000000.1 & 1.94 & 41.1 & 1859 & 3 & Sauerkraut \\
\hline NZ_MKGH01000040.1 & 1.95 & 41.0 & 1878 & $\sim$ & Cacao bean fermentation \\
\hline NZ_MKGG01000009.1 & 1.91 & 41.0 & 1847 & $\sim$ & Cacao bean fermentation \\
\hline NZ_BJVN01000001.1 & 1.90 & 41.1 & 1822 & 1 & Moto starter of sake \\
\hline NZ_AP017929.1 & 1.94 & 41.2 & 1834 & 1 & Moto starter of sake \\
\hline NZ_AZDN01000001.1 & 1.91 & 41.0 & 1818 & $\sim$ & Moto starter of sake \\
\hline NZ_MKDI01000019.1 & 1.93 & 41.0 & 1849 & $\sim$ & $\sim$ \\
\hline NZ_BKAA01000001.1 & 1.97 & 41.0 & 1920 & $\sim$ & $\sim$ \\
\hline NC_007576.1/CR936503.1 & 1.88 & 41.3 & 1777 & 0 & $\sim$ \\
\hline BALW01000001.1 & 1.91 & 41.0 & $\sim$ & $\sim$ & $\sim$ \\
\hline NZ_PUFE01000027.1 & 1.94 & 41.1 & 1838 & $\sim$ & $\sim$ \\
\hline NZZ_LT907931.1 & 1.90 & 41.1 & 1782 & 0 & $\sim$ \\
\hline NZ_MKGGB01000012.1 & 1.99 & 41.0 & 1900 & $\sim$ & $\sim$ \\
\hline NZ_MKDL01000023.1 & 1.97 & 40.9 & 1890 & $\sim$ & $\sim$ \\
\hline NZ_MKDJ00000000.1 & 1.92 & 41.1 & 1848 & $\sim$ & $\sim$ \\
\hline NZ_MKDD00000000.1 & 2.01 & 41.0 & 1926 & $\sim$ & $\sim$ \\
\hline NZ̄_BJLN00000000.1 & 1.94 & 41.1 & 1855 & $\sim$ & $\sim$ \\
\hline NZ_MKDE00000000.1 & 1.95 & 40.9 & 1885 & $\sim$ & $\sim$ \\
\hline
\end{tabular}

$\sim=$ Unavailable. 
Table 5. Characteristics' analysis of L. sakei plasmids.

\begin{tabular}{|c|c|c|c|c|}
\hline Accession No. & Size (bp) & GC (\%) & Genes No. & Origin \\
\hline MW265923 & 74,183 & 40.0 & 75 & Yak feces \\
\hline MW265924 & 8784 & 35.0 & 7 & Yak feces \\
\hline MW265925 & 4034 & 35.0 & 6 & Yak feces \\
\hline NZ_ASTI01000039.1 & 20,510 & 37.6 & 17 & Sausage \\
\hline NZ_LT960791.1 & 33,463 & 41.2 & 28 & Sausage \\
\hline NZ_LT960792.1 & 13,205 & 43.5 & 14 & Sausage \\
\hline NZ_LT960782.1 & 46,347 & 39.2 & 43 & Sausage \\
\hline NZ_LT960783.1 & 1526 & 40.2 & 2 & Sausage \\
\hline NZ_CP020460.1 & 84,581 & 34.5 & 80 & Food \\
\hline NZ_CP020461.1 & 26,098 & 40.4 & 21 & Food \\
\hline NZ_CP022710.1 & 75,468 & 41.5 & 57 & Water \\
\hline NZ_CP022711.1 & 11,504 & 34.6 & 10 & Water \\
\hline NZ_AP017932.1 & 33,266 & 40.0 & 32 & Microbial mat material \\
\hline NZ_AP017933.1 & 6196 & 35.9 & 6 & Microbial mat material \\
\hline NZ_AP017934.1 & 4315 & 35.3 & 5 & Microbial mat material \\
\hline NZ_LT960778.1 & 31,701 & 37.3 & 27 & Human feces \\
\hline NZ_LT960779.1 & 12,663 & 43.4 & 13 & Human feces \\
\hline NZ_LT960780.1 & 11,068 & 39.3 & 9 & Human feces \\
\hline NZ_LT960789.1 & 47,094 & 40.7 & 38 & Beef carpaccio \\
\hline NZ_LT960786.1 & 11,996 & 44.5 & 13 & Beef carpaccio \\
\hline NZ_LT960787.1 & 11,156 & 39.5 & 8 & Beef carpaccio \\
\hline NZ_LT960785.1 & 57,338 & 38.8 & 50 & Beef carpaccio \\
\hline NZ_CP046038.1 & 53,648 & 39.5 & 53 & Kimchi \\
\hline NZ_CP046039.1 & 20,312 & 38.5 & 21 & Kimchi \\
\hline NZ_CP020807.1 & 13,019 & 41.2 & 9 & Kimchi \\
\hline NZ_CP020808.1 & 13,083 & 38.1 & 10 & Kimchi \\
\hline NZ_CP025137.1 & 42,297 & 41.4 & 32 & Kimchi \\
\hline NZ_CP025138.1 & 14,883 & 36.3 & 20 & Kimchi \\
\hline NZ_CP025207.1 & 45,431 & 40.4 & 42 & Kimchi \\
\hline NZ_CP025208.1 & 44,839 & 38.5 & 38 & Kimchi \\
\hline NZ_CP025204.1 & 75,290 & 41.1 & 66 & Kimchi \\
\hline NZ_CP025205.1 & 14,876 & 36.3 & 20 & Kimchi \\
\hline NZ_CM010625.1 & 11,246 & 39.7 & 8 & Sauerkraut \\
\hline NZ_CM010626.1 & 6593 & 35.9 & 8 & Sauerkraut \\
\hline NZ_CM010627.1 & 2499 & 33.8 & 3 & Sauerkraut \\
\hline NZ_CP032636.1 & 51,286 & 41.9 & 40 & Raw cow milk \\
\hline NZ_CP032634.1 & 51,286 & 41.9 & 42 & Raw cow milk \\
\hline NZ_CP032641.1 & 51,284 & 41.9 & 39 & Fermented vegetables \\
\hline NZ_CP032653.1 & 51,286 & 41.9 & 39 & Fermented vegetables \\
\hline NZ_AP017930.1 & 6214 & 36.0 & 7 & Moto starter of sake \\
\hline NZ_CP059698.1 & 56,165 & 41.1 & 48 & $\sim$ \\
\hline NC_004942.1 & 12,959 & 38.1 & 13 & $\sim$ \\
\hline EF605268.1 & 5031 & 36.7 & 3 & $\sim$ \\
\hline EU555173.1 & 1790 & 34.0 & 2 & $\sim$ \\
\hline
\end{tabular}

\section{Discussion}

In the current study, we performed genome sequencing of L. sakei via both the Nanopore and Illumina sequencing platforms. The genome size, GC content, and number of coding proteins (1943) of the yak L. sakei isolates were compared to previously reported strains (Table 4) $[3,18,19,38-40]$. The number of rRNA genes (22) of L. sakei was higher than most of the previously reported isolates (9 21). Interestingly, most of the previously reported L. sakei strains had 0 2 plasmids, with lengths ranging from $1526 \mathrm{bp}$ to $84,581 \mathrm{bp}$, while the present yak isolates had three plasmids, with lengths of 4034 74,183 bp (Table 5). 
A total of 49 repeated RNA genes were found in the L. sakei genome, with a high redundancy, which may promote the bacterium ability to flourish in a complex microbial environment (Figure 2) [40]. In the KEGG annotation, we found that the L. sakei genome was rich in energy metabolism-related genes (Figure 7). In the 72 "ko-" signaling pathways, carbohydrate-like glycolysis (ko00010), pentose phosphate (ko0030), pentose and glucuronate interconversions (ko00040), fructose and mannose metabolism (ko00051), galactose metabolism (ko00052), starch and sucrose metabolism (ko00500), amino sugar and nucleotide sugar metabolism (ko00520), and pyruvate metabolism (ko00620) were found. Lipid pathways, such as fatty acid biosynthesis (ko00061), fatty acid degradation (ko00071), glycerolipid metabolism (ko00561), glycerophospholipid metabolism (ko00564), glyoxylate and dicarboxylate metabolism (ko00630), propanoate metabolism (ko00640), butanoate metabolism (ko00650), and fatty acid metabolism (ko01212) were uncovered. ATP-related oxidative phosphorylation (ko00190) and phosphotransferase system (PTS) (ko02060), with essential carbohydrate and lipid signaling pathways, may play an important role in promoting host energy storage and metabolism, especially in harsh conditions. PTS is comprised of two cytoplasmic phosphoryl proteins and sugar-specific enzyme II complexes, which have many regulatory functions in metabolism (carbon, nitrogen, and phosphate), transport (chemotaxis and potassium), and pathogen virulence [41,42]. Bacteria using PTS to transport carbohydrates into the bacterial cells contribute to metabolism [43]. These results add to the evidence for specific adaptation characteristics of the L. sakei yak strain. Interestingly, besides $\beta$-lactam resistance (ko01501) and cationic antimicrobial peptide resistance (ko01530) pathways, antibacterial signaling, e.g., Streptomycin (ko00521) during Staphylococcus aureus infection (ko05150) may keep yaks from being infected by specific pathogens, as Staphylococcus aureus can modulate the sensitivity to cationic antimicrobial peptides to decrease the immune response (https://www.kegg.jp/dbgetbin/www_bget?ko05150) [44]. Our previous study also confirmed that this L. sakei strain was not only resistant to commonly used antibiotics by letting them survive during the treatment of Staphylococcus aureus infection, but also has strong antibacterial ability to Staphylococcus aureus in vitro [5]. Other pathways like longevity regulating pathway-worm (https://www.kegg.jp/dbget-bin/www_ bget?ko04922), glucagon signaling pathway (https://www.kegg.jp/dbget-bin/www_bget?ko04922), and central carbon metabolism in cancer (https://www.kegg.jp/dbget-bin/www_bget?ko05230) were signaling related to glucose metabolisms and mitochondrial respiration, which may indicate the probiotic characteristics of this bacterium. However, further study is needed to evaluate such signaling.

The gut microbiota genome (CAZys encoded) contributes significantly to host carbohydrate disintegration, which has been found to be indispensable in human nutrition [45]. CAZy annotation uncovered that 35 and 38 genes encode glycosyl transferases (GTs) and glycoside hydrolases (GHs) in the L. sakei genome, respectively (Figure 6). Key enzyme genes of GTs of L. sakei were in line with those in L. pentosus (29), while GHs were considerably higher than in L. pentosus (10) [45]. These GHs are necessary for glycosidic bond hydrolysis. Its richness in yak strains may be beneficial for carbohydrate metabolism.

\section{Conclusions}

This study provides an overview of the genome and reports on unique genetic properties of probiotic L. sakei isolated from yak feces. Genomic analysis can determine the properties of this strain and may show the application of new biotechnology to key strains in the industry. However, further studies of the molecular and physiological properties of released metabolic products are required in order to understand the nature of the association of these probiotics with its metabolites. We hope that future research will help in understanding the biology of metabolites better, and provide new insights into the interactions between metabolites and bacteria.

Supplementary Materials: The following are available online at http://www.mdpi.com/2073-4425/11/12/1527/s1, Figure S1: Phylogenetic tree of the L. sakei yak isolate and references strains. The tree was constructed using software MEGA 6.0 by the neighbor-joining method, based on whole genome sequences with 1000 replications in bootstrap testing. 
Author Contributions: Conceptualization, K.L., J.L. (Jiakui Li) and D.Q.; methodology, K.L. and J.L. (Juanjuan Li); software, K.L.; validation, K.L., J.L. (Juanjuan Li), Z.Z. and M.F.A.K.; formal analysis, K.L., Y.W. and A.L.; writing-original draft preparation, K.L. and M.S.; writing-review and editing, K.L., Z.A.B. and A.I.A.; supervision, J.L. (Jiakui Li) and D.Q.; project administration, J.L. (Jiakui Li); funding acquisition, J.L. (Jiakui Li). All authors have read and agreed to the published version of the manuscript.

Funding: This research was funded by the China Postdoctoral Science Foundation (grant number 2020M672378); China Agriculture Research System (grant number CARS-37); and Tibet Autonomous Region Science Fund (grant number ZDZX2018000043).

Acknowledgments: We give thanks for the sequencing support from Bioyigene Biotechnology Co., Ltd. (Wuhan, China).

Conflicts of Interest: The authors declare no conflict of interest.

\section{References}

1. Sanchez, B.; Delgado, S.; Blanco-Miguez, A.; Lourenco, A.; Gueimonde, M.; Margolles, A. Probiotics, gut microbiota, and their influence on host health and disease. Mol. Nutr. Food Res. 2017, 61. [CrossRef] [PubMed]

2. Hill, C.; Guarner, F.; Reid, G.; Gibson, G.R.; Merenstein, D.J.; Pot, B.; Morelli, L.; Canani, R.B.; Flint, H.J.; Salminen, S.; et al. Expert consensus document. The International Scientific Association for Probiotics and Prebiotics consensus statement on the scope and appropriate use of the term probiotic. Nat. Rev. Gastroenterol. Hepatol. 2014, 11, 506-514. [CrossRef] [PubMed]

3. Kim, K.H.; Chun, B.H.; Baek, J.H.; Roh, S.W.; Lee, S.H.; Jeon, C.O. Genomic and metabolic features of Lactobacillus sakei as revealed by its pan-genome and the metatranscriptome of kimchi fermentation. Food Microbiol. 2020, 86, 103341. [CrossRef]

4. Verplaetse, E.; Andre-Leroux, G.; Duhutrel, P.; Coeuret, G.; Chaillou, S.; Nielsen-Leroux, C.; Champomier-Verges, M.-C. Heme Uptake in Lactobacillus sakei Evidenced by a New Energy Coupling Factor (ECF)-Like Transport System. Appl. Environ. Microbiol. 2020, 86. [CrossRef]

5. Liu, J.; Wang, Y.; Li, A.; Iqbal, M.; Zhang, L.; Pan, H.; Liu, Z.; Li, J. Probiotic potential and safety assessment of Lactobacillus isolated from yaks. Microbial. Pathog. 2020, 145, 104213. [CrossRef]

6. Lee, S.-Y.; Jeong, J.-J.; Kim, K.-A.; Kim, D.-H. Lactobacillus sakei OK67 ameliorates collagen-induced arthritis in mice by inhibiting NF-кB activation and restoring Th17/Treg cell balance. J. Funct. Foods 2015, 18, 501-511. [CrossRef]

7. Rather, I.A.; Bajpai, V.K.; Huh, Y.S.; Han, Y.K.; Bhat, E.A.; Lim, J.; Paek, W.K.; Park, Y.H. Probiotic Lactobacillus sakei proBio-65 Extract Ameliorates the Severity of Imiquimod Induced Psoriasis-Like Skin Inflammation in a Mouse Model. Front. Microbiol. 2018, 9, 1021. [CrossRef]

8. Seo, S.; Shin, J.-S.; Lee, W.-S.; Rhee, Y.K.; Cho, C.-W.; Hong, H.-D.; Lee, K.-T. Anti-colitis effect of Lactobacillus sakei $\mathrm{K} 040706$ via suppression of inflammatory responses in the dextran sulfate sodium-induced colitis mice model. J. Funct. Foods 2017, 29, 256-268. [CrossRef]

9. Jung, J.Y.; Shin, J.S.; Lee, S.G.; Rhee, Y.K.; Cho, C.W.; Hong, H.D.; Lee, K.T. Lactobacillus sakei K040706 evokes immunostimulatory effects on macrophages through TLR 2-mediated activation. Int. Immunopharmacol. 2015, 28, 88-96. [CrossRef] [PubMed]

10. Lim, S.M.; Jeong, J.J.; Woo, K.H.; Han, M.J.; Kim, D.H. Lactobacillus sakei OK67 ameliorates high-fat diet-induced blood glucose intolerance and obesity in mice by inhibiting gut microbiota lipopolysaccharide production and inducing colon tight junction protein expression. Nutr. Res. 2016, 36, 337-348. [CrossRef] [PubMed]

11. Woo, S.; Kim, J.; Lee, Y.; Kim, N.; Hahn, Y. Effect of Lactobacillus sakei supplementation in children with atopic eczema-dermatitis syndrome. Ann. Allergy Asthma Immunol. 2010, 104, 343-348. [CrossRef] [PubMed]

12. Li, K.; Gao, J.; Shahzad, M.; Han, Z.; Nabi, F.; Liu, M.; Zhang, D.; Li, J. Seroprevalence of Toxoplasma gondii infection in yaks (Bos grunniens) on the Qinghai-Tibetan Plateau of China. Vet. Parasitol. 2014, 205, 354-356. [CrossRef] [PubMed]

13. Li, K.; Li, Z.; Zeng, Z.; Li, A.; Mehmood, K.; Shahzad, M.; Gao, K.; Li, J. Prevalence and molecular characterization of Cryptosporidium spp. in yaks (Bos grunniens) in Naqu, China. Microb. Pathog. 2020, 144, 104190. [CrossRef] [PubMed] 
14. Qiu, Q.; Zhang, G.; Ma, T.; Qian, W.; Wang, J.; Ye, Z.; Cao, C.; Hu, Q.; Kim, J.; Larkin, D.M.; et al. The yak genome and adaptation to life at high altitude. Nat. Genet. 2012, 44, 946-949. [CrossRef] [PubMed]

15. Fan, Q.S.; Wanapat, M.; Yan, T.H.; Hou, F.J. Altitude influences microbial diversity and herbage fermentation in the rumen of yaks. BMC Microbiol. 2020, 20, 370. [CrossRef]

16. Wu, D.W.; Vinitchaikul, P.; Deng, M.Y.; Zhang, G.R.; Sun, L.Y.; Wang, H.X.; Gou, X.; Mao, H.M.; Yang, S.L. Exploration of the effects of altitude change on bacteria and fungi in the rumen of yak (Bos grunniens). Arch. Microbiol. 2020. [CrossRef]

17. Cryan, J.F.; Dinan, T.G. Mind-altering micro-organisms: The impact of the gut microbiota on brain and behaviour. Nat. Rev. Neurosci. 2012, 13, 701-712. [CrossRef]

18. Kwun, S.Y.; Yoon, J.A.; Park, E.H.; Kim, M.D. Complete genome sequence data of Lactobacillus sakei MBEL1397 isolated from kimchi. Data Brief 2020, 31, 105740. [CrossRef]

19. Eisenbach, L.; Geissler, A.J.; Ehrmann, M.A.; Vogel, R.F. Comparative genomics of Lactobacillus sakei supports the development of starter strain combinations. Microbiol. Res. 2019, 221, 1-9. [CrossRef]

20. Kato, S.; Oikawa, T. Genome Sequence of Lactobacillus sakei LK-145 Isolated from a Japanese Sake Cellar as a High Producer of d-Amino Acids. Genome Announc. 2017, 5. [CrossRef]

21. Jans, C.; Lagler, S.; Lacroix, C.; Meile, L.; Stevens, M.J.A. Complete Genome Sequences of Lactobacillus curvatus KG6, L. curvatus MRS6, and Lactobacillus sakei FAM18311, Isolated from Fermented Meat Products. Genome Announc. 2017, 5. [CrossRef] [PubMed]

22. Tritt, A.; Eisen, J.A.; Facciotti, M.T.; Darling, A.E. An integrated pipeline for de novo assembly of microbial genomes. PLoS ONE 2012, 7, e42304. [CrossRef]

23. Bankevich, A.; Nurk, S.; Antipov, D.; Gurevich, A.A.; Dvorkin, M.; Kulikov, A.S.; Lesin, V.M.; Nikolenko, S.I.; Pham, S.; Prjibelski, A.D.; et al. SPAdes: A new genome assembly algorithm and its applications to single-cell sequencing. J. Comput. Biol. 2012, 19, 455-477. [CrossRef] [PubMed]

24. Chin, C.S.; Peluso, P.; Sedlazeck, F.J.; Nattestad, M.; Concepcion, G.T.; Clum, A.; Dunn, C.; O’Malley, R.; Figueroa-Balderas, R.; Morales-Cruz, A.; et al. Phased diploid genome assembly with single-molecule real-time sequencing. Nat. Methods 2016, 13, 1050-1054. [CrossRef] [PubMed]

25. Koren, S.; Walenz, B.P.; Berlin, K.; Miller, J.R.; Bergman, N.H.; Phillippy, A.M. Canu: Scalable and accurate long-read assembly via adaptive k-mer weighting and repeat separation. Genome Res. 2017, 27, 722-736. [CrossRef] [PubMed]

26. Marcais, G.; Delcher, A.L.; Phillippy, A.M.; Coston, R.; Salzberg, S.L.; Zimin, A. MUMmer4: A fast and versatile genome alignment system. PLoS Comput. Biol. 2018, 14, e1005944. [CrossRef] [PubMed]

27. Walker, B.J.; Abeel, T.; Shea, T.; Priest, M.; Abouelliel, A.; Sakthikumar, S.; Cuomo, C.A.; Zeng, Q.; Wortman, J.; Young, S.K.; et al. Pilon: An integrated tool for comprehensive microbial variant detection and genome assembly improvement. PLoS ONE 2014, 9, e112963. [CrossRef] [PubMed]

28. Besemer, J.; Lomsadze, A.; Borodovsky, M. GeneMarkS: A self-training method for prediction of gene starts in microbial genomes. Implications for finding sequence motifs in regulatory regions. Nucleic Acids Res. 2001, 29, 2607-2618. [CrossRef]

29. Lowe, T.M.; Eddy, S.R. tRNAscan-SE: A program for improved detection of transfer RNA genes in genomic sequence. Nucleic Acids Res. 1997, 25, 955-964. [CrossRef]

30. Burge, S.W.; Daub, J.; Eberhardt, R.; Tate, J.; Barquist, L.; Nawrocki, E.P.; Eddy, S.R.; Gardner, P.P.; Bateman, A. Rfam 11.0: 10 years of RNA families. Nucleic Acids Res. 2013, 41, D226-D232. [CrossRef]

31. Moriya, Y.; Itoh, M.; Okuda, S.; Yoshizawa, A.C.; Kanehisa, M. KAAS: An automatic genome annotation and pathway reconstruction server. Nucleic Acids Res. 2007, 35, W182-W185. [CrossRef] [PubMed]

32. Stothard, P.; Wishart, D.S. Circular genome visualization and exploration using CGView. Bioinformatics 2005, 21, 537-539. [CrossRef] [PubMed]

33. Petersen, T.N.; Brunak, S.; von Heijne, G.; Nielsen, H. SignalP 4.0: Discriminating signal peptides from transmembrane regions. Nat. Methods 2011, 8, 785-786. [CrossRef] [PubMed]

34. Chen, Y.; Yu, P.; Luo, J.; Jiang, Y. Secreted protein prediction system combining CJ-SPHMM, TMHMM, and PSORT. Mamm. Genome 2003, 14, 859-865. [CrossRef] [PubMed]

35. Buchfink, B.; Xie, C.; Huson, D.H. Fast and sensitive protein alignment using DIAMOND. Nat. Methods 2015, 12, 59-60. [CrossRef] [PubMed] 
36. Finn, R.D.; Bateman, A.; Clements, J.; Coggill, P.; Eberhardt, R.Y.; Eddy, S.R.; Heger, A.; Hetherington, K.; Holm, L.; Mistry, J.; et al. Pfam: The protein families database. Nucleic Acids Res. 2014, 42, D222-D230. [CrossRef] [PubMed]

37. Seemann, T. Prokka: Rapid prokaryotic genome annotation. Bioinformatics 2014, 30, 2068-2069. [CrossRef]

38. Kant, R.; Blom, J.; Palva, A.; Siezen, R.J.; de Vos, W.M. Comparative genomics of Lactobacillus. Microb. Biotechnol. 2011, 4, 323-332. [CrossRef]

39. Loux, V.; Coeuret, G.; Zagorec, M. Complete and Draft Genome Sequences of Nine Lactobacillus sakei Strains Selected from the Three Known Phylogenetic Lineages and Their Main Clonal Complexes. Genome Announc. 2018, 6, e00082-00018. [CrossRef]

40. Chaillou, S.; Champomier-Verges, M.C.; Cornet, M.; Crutz-Le Coq, A.M.; Dudez, A.M.; Martin, V.; Beaufils, S.; Darbon-Rongere, E.; Bossy, R.; Loux, V.; et al. The complete genome sequence of the meat-borne lactic acid bacterium Lactobacillus sakei 23K. Nat. Biotechnol. 2005, 23, 1527-1533. [CrossRef]

41. Liu, X.; Zeng, J.; Huang, K.; Wang, J. Structure of the mannose transporter of the bacterial phosphotransferase system. Cell Res. 2019, 29, 680-682. [CrossRef] [PubMed]

42. Lim, S.; Seo, H.S.; Jeong, J.; Yoon, H. Understanding the multifaceted roles of the phosphoenolpyruvate: Phosphotransferase system in regulation of Salmonella virulence using a mutant defective in ptsI and crr expression. Microbiol. Res. 2019, 223-225, 63-71. [CrossRef] [PubMed]

43. Kotrba, P.; Inui, M.; Yukawa, H. Bacterial phosphotransferase system (PTS) in carbohydrate uptake and control of carbon metabolism. J. Biosci. Bioeng. 2001, 92, 502-517. [CrossRef]

44. Laarman, A.; Milder, F.; Strijp, J.V.; Rooijakkers, S. Complement inhibition by gram-positive pathogens: Molecular mechanisms and therapeutic implications. J. Mol. Med. 2010, 88, 115-120. [CrossRef] [PubMed]

45. Ye, K.; Li, P.; Gu, Q. Complete genome sequence analysis of a strain Lactobacillus pentosus ZFM94 and its probiotic characteristics. Genomics 2020, 112, 3142-3149. [CrossRef] [PubMed]

Publisher's Note: MDPI stays neutral with regard to jurisdictional claims in published maps and institutional affiliations.

(C) 2020 by the authors. Licensee MDPI, Basel, Switzerland. This article is an open access article distributed under the terms and conditions of the Creative Commons Attribution (CC BY) license (http://creativecommons.org/licenses/by/4.0/). 